\title{
Successful Treatment of Genital Warts with Ingenol Mebutate Monitored with Optical Coherence Tomography and Reflectance Confocal Microscopy
}

\author{
Markus Reinholz*, Benjamin M. Clanner-Engelshofen*, Markus V. Heppt, Yoji Hirai ${ }^{1}$, \\ Thomas Ruzicka, Carola Berking, Tanja von Braunmühl
}

Department of Dermatology and Allergy, University Hospital of Munich (LMU), Munich, Germany, ${ }^{1}$ Department of Dermatology, Okayama University Graduate School of Medicine, Dentistry and Pharmaceutical Sciences, Kawasaki Medical School, Okayama, Japan

Ingenol mebutate (IM) is approved for the treatment of actinic keratosis and induces cell death in precancerous lesions. The efficacy of IM in the treatment of genital warts was investigated in a therapy-refractory patient. The 74-year-old male was treated with IM gel for three consecutive days. Treatment course and efficacy were evaluated by clinical inspection and non-invasive diagnostics namely optical coherence tomography (OCT) and reflectance confocal microscopy (RCM). Within 24 to 48 hours IM induced a strong local inflammatory reaction. One week later a complete response was observed. OCT and RCM showed a strong reaction after treatment with erosions, swelling of cells, and a subepidermal dark band in representative lesions. IM has the advantage of a short treatment period in contrast to other topical treatments and shows a promising clinical outcome. Larger studies are needed to validate the data. (Ann Dermatol 31(4) $434 \sim 437,2019$ )

Received October 31, 2017, Revised March 29, 2018, Accepted for publication April 6, 2018

Corresponding author: Markus Reinholz, Department of Dermatology and Allergy, University Hospital of Munich (LMU), Frauenlobstr. 9-11, 80337 Munich, Germany. Tel: 49-89-4400-56010, Fax: 49-89-4400-56389, E-mail: markus.reinholz@med.uni-muenchen.de ORCID: https://orcid.org/0000-0002-0465-3506

*These authors have equally contributed to the article.

This is an Open Access article distributed under the terms of the Creative Commons Attribution Non-Commercial License (http://creativecommons. org/licenses/by-nc/4.0) which permits unrestricted non-commercial use, distribution, and reproduction in any medium, provided the original work is properly cited.

Copyright (c) The Korean Dermatological Association and The Korean Society for Investigative Dermatology

\section{-Keywords-}

Condylomata acuminata, Microscopy, confocal, Neoplasms, Optical coherence tomography

\section{INTRODUCTION}

Infections with human papillomavirus (HPV) are a modern pandemic with millions of people being infected each year. The 170 different types of this double-stranded DNA virus are divided into low- and high-risk virus classes according to their oncogenic potential ${ }^{1}$. The high-risk subtypes are commonly found in cervical, penile, or anal dysplasias $^{2}$ with the potential to progress to carcinomas after a long-standing infection.

Low-risk virus subtypes can lead to the development of genital warts, which are biologically benign but very bothersome and stigmatizing for the patient ${ }^{3}$. Moreover HPV is highly contagious; therefore genital warts are a very common manifestation of HPV infection in sexually active adults. Sexual contact with an HPV-infected individual results in a 75 percent chance of contracting the virus, with additional risk factors being immunosuppression, unprotected intercourse, smoking, or a history of sexually transmitted diseases ${ }^{4}$.

For the treatment of genital warts various topical medications including 5-fluorouracil, sinecatechins, trichloroacetic acid, and imiquimod are available. Other treatment options include cryosurgery, laser, electrocautery, or surgical excision, but with higher risk of scarring. Recently, ingenol mebutate (IM) has been approved as a new agent for topical treatment of actinic keratosis ${ }^{5}$. IM is one of the active compounds of the plant Euphorbia peplus L. The 
hydrophobic diterpene ester called ingenol-3-angelate was identified as an active ingredient. Usage of wild E. peplus for treatment of various medical conditions is known from ancient times.

The objective of our investigation was the initiation of an immune response to the genital warts through topical application of IM. We hypothesized that IM would trigger apoptosis and necrosis of the affected cells and additionally induce an antigenic immune response.

Modern imaging techniques such as optical coherence tomography (OCT) and reflectance confocal microscopy (RCM) have proven useful in practice for the noninvasive diagnosis of non-melanoma skin cancer and treatment monitoring ${ }^{6-8}$.

Reaction and response to treatment were mainly evaluated by clinical examination, while OCT and RCM were used to monitor the response, similar to monitoring the therapeutic success of IM gel in actinic keratosis ${ }^{9}$.

\section{CASE REPORT}

In this case report, we evaluated a 74-year-old male patient who had several unsuccessful standard treatments previously. The patient presented with 15 genital warts in the area of the radix penis and scrotum (Fig. 1). The patient was treated at the Department of Dermatology, University Hospital of Munich (Ludwig Maximilian University, LMU), after obtaining written informed consent for the individual off-label use of topical ingenol mebutate in geni-
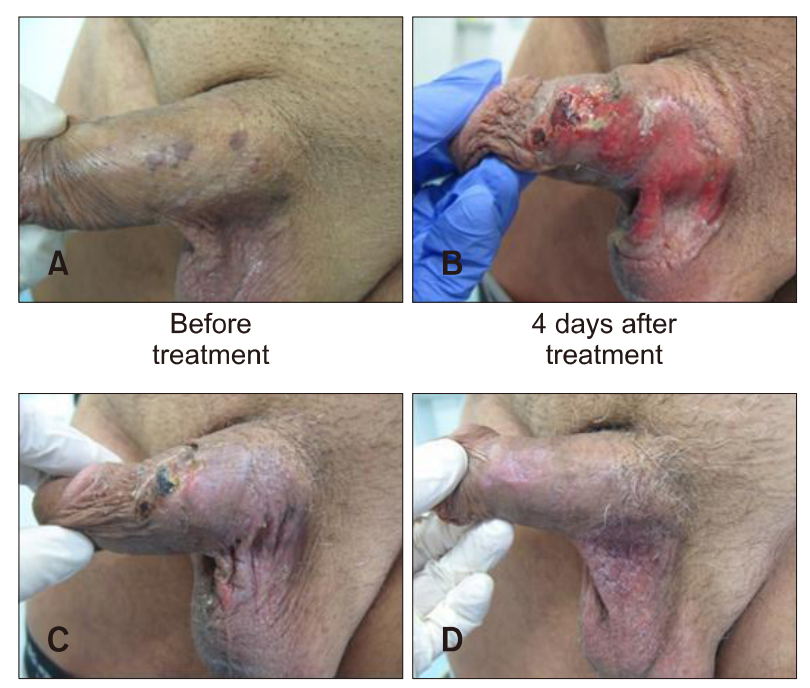

7 days after treatment

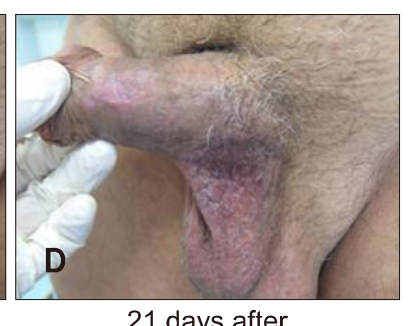

21 days after treatment

Fig. 1. Therapeutic follow-up. Patient (A) before treatment, (B) 4 days, (C) 7 days, and (D) 21 days after application of ingenol mebutate. Written informed consent to publish the photos from the patient was obtained. tal warts. A single dose of $0.47 \mathrm{~g}$ IM gel $(150 \mu \mathrm{g} / \mathrm{g}$, daily dose: $70.5 \mu \mathrm{g} \mathrm{IM;} \mathrm{Picato}{ }^{\circledR}$; LEO Pharma A/S, Ballerup, Danmark) was applied topically for three consecutive days in a predefined treatment area of $25 \mathrm{~cm}^{2}$.

The site of infection was evaluated and monitored clinically as well as documented via OCT and RCM on baseline and day 4, 7, and 21 after initial treatment.

The initial clinical evaluation revealed 15 condylomata acuminata with typical features of papillomatous or verrucous tumors or plaques with brownish-red coloration.

\section{Non-invasive imaging}

For non-invasive imaging the following commercially available devices were used: a Fourier-domain OCT system (Vivosight $^{\mathbb{R}}$; Michelson Diagnostics, Kent, UK) with a $1,310 \mathrm{~nm}$ multi-beam laser providing a penetration depth of 1.5 to $2 \mathrm{~mm}$ and a resolution of 5 to $7.5 \mu \mathrm{m}$ and an in-vivo RCM device (Vivascope ${ }^{\circledR}$ 1500; Lucid-Tech Inc., Henrietta, NY, USA; Mavig GmbH, Munich, Germany) with a penetration depth of about $250 \mu \mathrm{m}$ and a resolution of 1.25 to $2.5 \mu \mathrm{m}^{10,11}$.

OCT and RCM imaging was performed in one defined target lesion before and after seven and 21 days after treatment with IM gel.

\section{Clinical evaluation}

IM induced an inflammatory reaction after 24 hours in the treated area. This reaction lasted up to seven days with decreasing intensity (Fig. 1).

The observed local reactions were temporary and similar to previously described reactions seen after application in actinic keratosis ${ }^{12}$.

Erythema, flaking/scaling, swelling and erosion were observed between day two and four. Additionally crusting, vesiculation and pustulation were seen.

In the patient the warts disappeared completely and were not detectable even after three weeks, neither by clinical inspection (Fig. 1) nor by non-invasive imaging (OCT or RCM) (Fig. 2).

Three weeks after application of IM gel, the skin normalized without any sign of HPV infection (Fig. 1). A residual erythema was found in the patient after 21 days (Fig. 1D). No systemic side effects were observed. Post-treatment erythema was reported by the patient, but no other adverse event.

Six months after the treatment the patient was still in remission, so it can be assumed the treatment was successful.

\section{OCT and RCM}

Prior to treatment, the genital warts presented as papillomatous tumors with a broadening of the epidermis and 
A

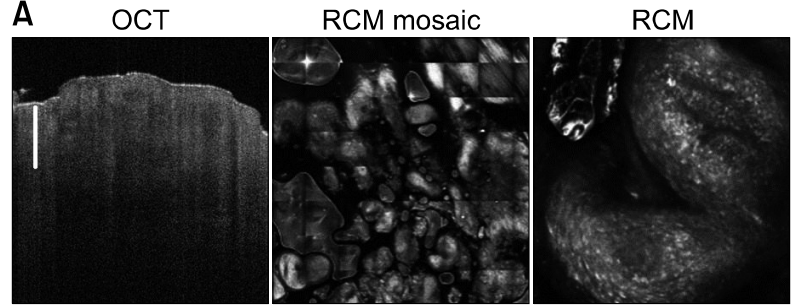

Before treatment

B

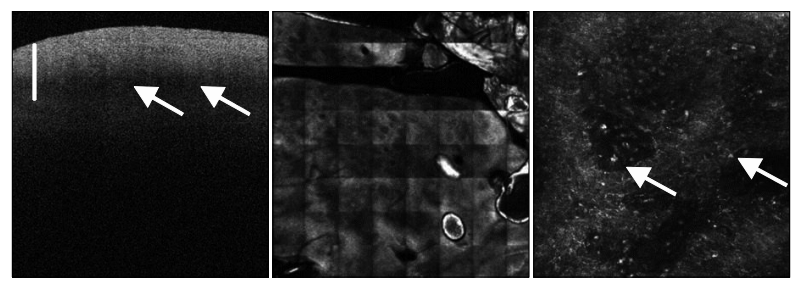

After treatment day 4

C

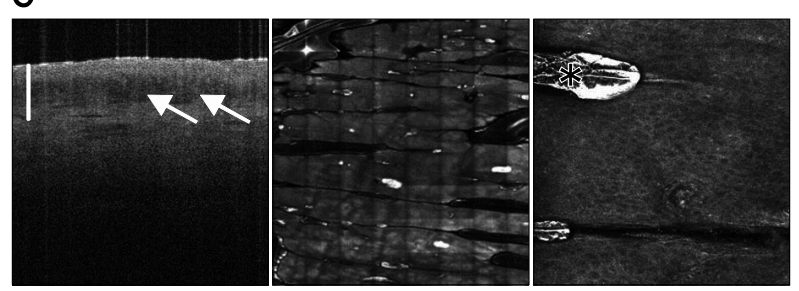

After treatment day 21

Fig. 2. Optical coherence tomography (OCT), overview reflectance confocal microscopy (RCM) mosaic, and single RCM imaging in therapeutic follow-up: (A) Patient before treatment with a verruciform lesion visible in OCT $(1.8 \times 0.6 \mathrm{~mm}$, scale bar $=0.5 \mathrm{~mm})$ and the overview RCM mosaic $(5 \times 5 \mathrm{~mm})$ at a superficial epidermal level in the single $\mathrm{RCM}$ image $(0.5 \times 0.5$ $\mathrm{mm}$ ) with bright epidermal cells. (B) On day 4, in OCT with a subepidermal dark band (arrows) compatible with inflammation/edema and dilated vessels in overview RCM at the level of dermoepidermal junction (DEJ), in single image RCM at the DEJ level bright particles (arrows) compatible with inflammatory cells are seen. (C) After 21 days in OCT still a subepidermal dark band (arrows) is present, in RCM vessels are still prominent (overview, at DEJ level), but epidermis shows a regular honeycomb pattern (single RCM at stratum corneum/stratum granulosum level, asterisk marks a bright artefact due to an immersion oil bubble).

sometimes keratotic changes including signal-intense dots intratumorally in OCT (Fig. 2).

In RCM the genital warts showed aggregated hyperplastic nodules in the Vivablock ${ }^{\circledR}$ (Mavig $\mathrm{GmbH}$ ) mosaic overview $(5 \times 5 \mathrm{~mm})$ of superficial layers and in the single RCM image $(0.5 \times 0.5 \mathrm{~mm})$ a broadened epidermis with signal-intense bright epidermal cells and hypervascularization (Fig. 2).

Four days after treatment start, OCT showed flattening of the epidermis and disappearance of layering. A signalpoor dark band sublesionally was characteristic and consistent with inflammatory reactions and edema (Fig. 2).
On day four multiple bright cells spreading throughout the epidermis were present in RCM imaging compatible with inflammatory cells, which showed disruption of cells and prominent vessels within the papillae (Fig. 2).

Three weeks after treatment, OCT imaging showed a still prevailing subepidermal signal-poor dark band. For the publishing of the photographic materials a patient's consent form has been received.

\section{DISCUSSION}

In the conventional topical therapies of genital warts the treatment success depends mainly on the adherence of the patients. Due to the often long-term treatment course the patients commonly fail to maintain proper procedure or develop uncomfortable side effects like pain or burning sensations.

The common treatment options for genital warts include the following therapies: Podophyllotoxin shows high recurrence rates after clearance ${ }^{13}$ while imiquimod has lower recurrence rates ${ }^{14}$. The application of sinecatechins ointment and trichloroacetic acid has led to moderate clearance rates ${ }^{15}$.

Cryosurgery, electrosurgery, and scissors excision are additional invasive treatment options ${ }^{16,17}$. Particularly the topical drug treatments are associated with inconveniences for the patients as long-lasting, high-frequent application with partially severe side effects. Therefore the treatment with IM could serve as an alternative for the therapy of genital warts.

In contrast to the recently published case report of Braun et al. ${ }^{18}$, which described the single spot-like use of the 500 $\mu \mathrm{g} / \mathrm{g}$ formulation on multiple condylomata acuminata, the repetitive application of the $150 \mu \mathrm{g} / \mathrm{g}$ formulation leads to less severe local reactions including burning sensation and pain.

The mechanism of action of IM is not yet fully understood, but latest studies suggest a dual mode of action via both cellular necrosis and neutrophil-mediated antibody-dependent cellular cytotoxicity ${ }^{19}$. It was shown that within one to two hours of application, the exposure of cancerous cells to IM induces cellular necrosis ${ }^{20}$. IM gel destroys epidermal cells within hours and induces the production of antibodies that result in neutrophils targeted to kill any residual dysplastic epidermal cells, which is important for preventing relapses following treatment ${ }^{19}$. Therefore, in contrast to more invasive approaches the herein mentioned therapy has potentially less side effects like scarring. In comparison to hitherto available topical remedies the treatment with IM has the advantage of a reduced treatment time. 
In summary, IM may represent a novel treatment option for refractory genital warts. Even in a pretreated patient it showed a good clinical response and lasting results. Larger prospective randomized controlled trials are needed to objectify and evaluate this clinical concept.

\section{CONFLICTS OF INTEREST}

MR has received speaker's and advisor's fees by Galderma and MEDA Pharma $\mathrm{GmbH} \& \mathrm{Co}$. Kommanditgesellschaft, BMCE none, MVH none, $\mathrm{YH}$ none, TR has received speaker's and advisor's fees by Galderma; CB has received speaker's and advisor's fees by Almirall-Hermal, Biofrontera, Galderma, and LEO Pharma A/S. TvB and CB have received a research grant by LEO Pharma $A / S$. TVB has received speaker's fees by Almirall-Hermal. The OCT Vivosight ${ }^{\mathbb{R}}$ device used in this study has been provided by Michelson Diagnostics, UK, and the RCM Vivascope $1500^{\circledR}$ device used in this study has been provided Mavig $\mathrm{GmbH}$, Munich, Germany.

\section{ORCID}

Markus Reinholz, https://orcid.org/0000-0002-0465-3506

Benjamin M. Clanner-Engelshofen, https://orcid.org/0000-0001-9863-3380

Markus V. Heppt, https://orcid.org/0000-0003-4603-1825

Yoji Hirai, https://orcid.org/0000-0003-2201-6129

Thomas Ruzicka, https://orcid.org/0000-0002-9596-1749

Carola Berking, https://orcid.org/0000-0003-0229-8931

Tanja von Braunmühl, https://orcid.org/0000-0002-4510-7616

\section{REFERENCES}

1. Doorbar J. Molecular biology of human papillomavirus infection and cervical cancer. Clin Sci (Lond) 2006;110: 525-541.

2. Dietrich A, Hermans C, Heppt MV, Ruzicka T, Schauber J, Reinholz M. Human papillomavirus status, anal cytology and histopathological outcome in HIV-positive patients. J Eur Acad Dermatol Venereol 2015;29:2011-2018.

3. Rosales R, Rosales C. Immune therapy for human papillomaviruses-related cancers. World J Clin Oncol 2014;5: 1002-1019.

4. Yanofsky VR, Patel RV, Goldenberg G. Genital warts: a comprehensive review. J Clin Aesthet Dermatol 2012;5: 25-36.

5. Fallen RS, Gooderham M. Ingenol mebutate: an introduction. Skin Therapy Lett 2012;17:1-3.

6. Maier T, Braun-Falco M, Hinz T, Schmid-Wendtner $M H$, Ruzicka T, Berking C. Morphology of basal cell carcinoma in high definition optical coherence tomography: en-face and slice imaging mode, and comparison with histology. J
Eur Acad Dermatol Venereol 2013;27:e97-e104.

7. Maier T, Braun-Falco M, Laubender RP, Ruzicka T, Berking C. Actinic keratosis in the en-face and slice imaging mode of high-definition optical coherence tomography and comparison with histology. Br J Dermatol 2013;168:120-128.

8. Reinholz M, Gauglitz GG, Giehl K, Braun-Falco M, Schwaiger $\mathrm{H}$, Schauber J, et al. Non-invasive diagnosis of sweat gland dysplasia using optical coherence tomography and reflectance confocal microscopy in a family with anhidrotic ectodermal dysplasia (Christ-Siemens-Touraine syndrome). J Eur Acad Dermatol Venereol 2016;30:677-682.

9. Maier T, Cekovic D, Ruzicka T, Sattler EC, Berking C. Treatment monitoring of topical ingenol mebutate in actinic keratoses with the combination of optical coherence tomography and reflectance confocal microscopy: a case series. Br J Dermatol 2015;172:816-818.

10. von Braunmühl T, Welzel J. [Noninvasive diagnostic imaging in dermatology]. Hautarzt 2015;66:492. German.

11. von Braunmühl T. [Optical coherence tomography]. Hautarzt 2015;66:499-503. German.

12. Anderson L, Schmieder GJ, Werschler WP, Tschen EH, Ling MR, Stough DB, et al. Randomized, double-blind, doubledummy, vehicle-controlled study of ingenol mebutate gel $0.025 \%$ and $0.05 \%$ for actinic keratosis. J Am Acad Dermatol 2009;60:934-943.

13. von Krogh G, Szpak E, Andersson M, Bergelin I. Selftreatment using $0.25 \%-0.50 \%$ podophyllotoxin-ethanol solutions against penile condylomata acuminata: a placebocontrolled comparative study. Genitourin Med 1994;70: 105-109.

14. Schöfer H, Van Ophoven A, Henke U, Lenz T, Eul A. Randomized, comparative trial on the sustained efficacy of topical imiquimod 5\% cream versus conventional ablative methods in external anogenital warts. Eur J Dermatol 2006; 16:642-648.

15. Gross G, Meyer KG, Pres H, Thielert C, Tawfik H, Mescheder A. A randomized, double-blind, four-arm parallel-group, placebo-controlled Phase II/III study to investigate the clinical efficacy of two galenic formulations of Polyphenon E in the treatment of external genital warts. J Eur Acad Dermatol Venereol 2007;21:1404-1412.

16. Khawaja HT. Treatment of condyloma acuminatum. Lancet 1986;1:208-209.

17. Khawaja HT. Podophyllin versus scissor excision in the treatment of perianal condylomata acuminata: a prospective study. Br J Surg 1989;76:1067-1068.

18. Braun SA, Jansen TM, Homey B, Gerber PA. [Successful therapy of condylomata acuminata with ingenol mebutate]. Hautarzt 2015;66:223-225. German.

19. Rosen RH, Gupta AK, Tyring SK. Dual mechanism of action of ingenol mebutate gel for topical treatment of actinic keratoses: rapid lesion necrosis followed by lesion-specific immune response. J Am Acad Dermatol 2012;66:486-493.

20. Ogbourne SM, Suhrbier A, Jones B, Cozzi SJ, Boyle GM, Morris $M$, et al. Antitumor activity of 3-ingenyl angelate: plasma membrane and mitochondrial disruption and necrotic cell death. Cancer Res 2004;64:2833-2839. 